\title{
Pengaruh Pendidikan dan Pendapatan Orang Tua Terhadap Tingkat Pendidikan Anak Keluarga Nelayan Tradisional Kecamatan Seruyan Hilir Kabupaten Seruyan
}

\author{
Widy Astuti ${ }^{1}$, Holten Sion ${ }^{2}$, Dehen Erang ${ }^{3}$ \\ Program Magister Pendidikan Ekonomi, Pascasarjana Universitas Palangka Raya \\ *Correspondence author: windyastuti@gmail.com ; Tel.: +6282231071000
}

\begin{abstract}
This study was done at Seruyan Hilirsubdistrict of Seruyan regency to know whether there was an effect of parents 'education toward the level of children education in traditional fishermen family. Whether the parents' income had an effect toward the level of the traditional fishermen' children education and it was also to know the effect of parents' education and parents' income toward the level of children education in traditional fishermen of SeruyanHilirsubdistrict of Seruyan regency. The aim of this study was to know the effect of parents' education and parents' income toward the level of children education in traditional fishermen. The differences in the high level of education and the amount of parents' income whether had an effect on their children's education level. The study was one of a quantitative research method. The instrument of data collection on this study used questionnaires. The data analysis applied descriptive presentation and regression multiple. The technique of sample collection used Proportionate Stratified Random Sampling technique because the stratified population. The amount of sample was determined by using Isaac and Michael tables. The result of analysis showed that the significance value on the result of SPSS 16.0, the effect of parents' income toward the level of the traditional fishermen' children education was $0.00<0.05$, which was obviously variable $X_{1}$ and $X_{2}$ influenced the variable $Y$. The effect of parents' income toward the children education got $P$ value $<0.05(0.00<0.05)$, the $H_{0}$ rejected and $H_{1} a c c e p t e d$, it meant that there was a significant effect of fishermen income toward the level of the traditional fishermen' children education. According to the result of computation apparently show that $X_{1}$ and $X_{2}$ had an effect toward $Y$. Based on the table $R^{2}$ value (R square) was 0.676 or (67.6\%). It showed that the contributory percentage of the independent variable effect (Fishermen' education and income) toward dependent variable (the education of fishermen children) were $67.6 \%$.
\end{abstract}

Keywords: the parents' education, the parents' income, the education of fisherman children, the traditional fishermen

\begin{abstract}
Abstrak: Penelitian yang dilakukan di Kecamatan Seruyan Hilir Kabupaten Seruyan untuk mengetahui apakah terdapat pengaruh tingkat pendidikan orang tua terhadap tingkat pendidikan anak nelayan di Kecamatan Seruyan Hilir Kabupaten Seruyan, apakah terdapat pengaruh tingkat pendapatan orang tua terhadap tingkat pendidikan anak nelayan di Kecamatan Seruyan Hilir Kabupaten Seruyan dan apakah terdapat pengaruh tingkat pendidikan dan pendapatan orang tua terhadap tingkat pendidikan anak nelayan di Kecamatan Seruyan Hilir Kabupaten Seruyan. Tujuan penelitian ini adalah untuk mengetahui Pengaruh Pendidikan dan Pendapatan Orang tua Terhadap Tingkat Pendidikan anak Nelayan Tradisional. Perbedaan tingginya tingkat Pendidikan dan Besarnya Pendapatan Orang tua apakah mempunyai pengaruh terhadap Tingkat Pendidikan Anak nelayan tradisional Kecamatan Seruyan Hilir Kabupaten Seruyan. Penelitian ini merupakan jenis penelitian kuantitatif dengan metode pengumpulan data menggunakan kuesioner. Analisis yang digunakan adalah Deskriptif presentase dan regresi berganda Pengambilan sampel dilakukan menggunakan teknik Proportionate Stratifield Random Sampling karena populasi yang berstrata. Jumlah sampel di tentukan dengan menggunakan tabel Isaac dan Michael. Hasil analisis ternyata nilai Signifikansi pada hasil SPSS 16.0 pengaruh pendidikan orang tua terhadap tingkat pendidikan anak nelayan tradisional yaitu $0,00<0,05$, maka dengan demikian secara nyata variabel $X_{1}$ berpengaruh terhadap $Y$. Dan pengaruh pendapatan orang tua terhadap pendidikan anak Nilai $\mathrm{P}$ value $<0.05(0.00<0.05)$ maka $\mathrm{H}_{0}$ ditolak dan $\mathrm{H}_{1}$ diterima, artinya ada pengaruh secara signifikansi pendapatan nelayan terhadap tingkat pendidikan anak nelayan tradisional. Berdasarkan hasil perhitungan ternyata nilai Signifikansi yaitu $0,00<0,05$, maka dengan demikian secara nyata
\end{abstract}


variabel $X_{1}$ dan $X_{2}$ berpengaruh terhadap $Y$. Berdasarkan tabel diperoleh angka $R^{2}$ ( $R$ square ) sebesar 0.676 atau (67.6\%). Hal ini menunjukkan bahwa persentase sumbangan pengaruh variabel independen (pendidikan nelayan dan pendapatan nelayan) terhadap variabel dependen (pendidikan anak nelayan) sebesar 67.6\%.

Kata Kunci: Pendidikan Orang tua, pendapatan orang tua, pendidikan anak nelayan, nelayan tradisional

\section{PENDAHULUAN}

Sumber daya alam yang melimpah belum tentu menjadi jaminan bahwa suatu negara atau wilayah itu akan makmur, bila pendidikan manusianya yang mengelola sumber daya alam tersebut kurang mendapat perhatian. Upaya untuk peningkatkan kualitas sumber daya manusia merupakan tugas bersama pemerintah dengan seluruh lapisan masyarakat, pendidikan merupakan suatu proses menyangkut pendidikan anak bangsa. Peranan pemerintah dalam penyelenggaraan pendidikan sesuai dengan ketentuan dalam UU Nomor 20 tahun 2003 tentang Sistem Pendidikan Nasional. Tingkat pendapatan orang tua berpengaruh terhadap kemampuan orang tua dalam memenuhi kebutuhan pendidikan anak-anaknya. Orang tua yang memiliki pendidikan yang tinggi mampu memenuhi kebutuhan pendidikan anak-anaknya sampai jenjang pendidikan tinggi. Pekerjaan sebagai nelayan dipilih karena sesuai dengan keterampilan masyarakat setempat, sementara sumberdaya yang tersedia hanya laut dan sungai beserta isinya yang mempunyai nilai ekonomi. Sehingga tidak ada pilihan lain bagi masyarakat yang tinggal di sepanjang sungai dan pesisir laut selain menjadi nelayan yang berhubungan dengan sungai dan laut. Para nelayan di Kecamatan Seruyan Hilir ini bekerja secara turun temurun atau dari warisan keluarga sehingga untuk para pekerja biasanya berasal dari sanak saudara dan masyarakat sekitar. Dengan demikian masalah pendidikan nelayan terkadang diabaikan.

Rumusan masalah yang akan di kaji dalam penelitian ini adalah :

1. Apakah terdapat pengaruh tingkat pendidikan orang tua terhadap tingkat pendidikan anak nelayan di Kecamatan Seruyan Hilir Kabupaten Seruyan?

2. Apakah terdapat pengaruh tingkat pendapatan orang tua terhadap tingkat pendidikan anak nelayan di Kecamatan Seruyan Hilir Kabupaten Seruyan?

3. Apakah terdapat pengaruh tingkat pendidikan dan pendapatan orang tua terhadap tingkat pendidikan anak nelayan di Kecamatan Seruyan Hilir Kabupaten Seruyan?

Menurut M.I. Soelaiman, (2005) "Pendidikan merupakan usaha sadar yang dilakukan oleh seorang dewasa terhadap pihak lain yang belum dewasa agar mencapai kedewasaan". Artinya bahwa pendidikan merupakan suatu cara dimana lebih menekankan terhadap keterkaitannya antara peserta didik dan pendidik. Tujuan Sistem Pendidikan Nasional Berdasarkan UU. No.20 Tahun 2003 Pasal 3 bahwa "tujuan pendidikan nasional adalah mengembangkan potensi peserta didik agar menjadi manusia yang beriman dan bertakwa kepada Tuhan Yang Maha Esa, berakhlak mulia, sehat, berilmu, cakap, kreatif, mandiri, dan menjadi warga negara yang demokratis serta bertanggung jawab".

Menurut Sunardi dan Evers (2002) menyebutkan bahwa "pendapatan adalah seluruh penerimaan baik berupa barang maupun uang baik dari pihak lain maupun dari hasil sendiri, dengan jalan dinilai dengan sejumlah uang atau harga yang berlaku saat itu". Sedangkan menurut Sitorus (2004) Bahwa: Pendapatan nelayan adalah jumlah kegunaan yang dapat dihasilkan melalui usaha. Pada hakikatnya jumlah uang yang diterima oleh seorang produsen (nelayan/petani ikan) untuk produk yang dijualnya tergantung dari jumlah uang yang harus dikeluarkan oleh konsumen, jumlah produk yang dipasarkan dan biaya-biaya untuk menggerakkan produk ke pasar.

\section{METODE}

Penelitian ilmiah mendasarkan pada metode yang harus dipertanggungjawabkan kebenarannya dan mendasari pada teori-teori yang relevan. Oleh karena itu diperlukan pemilihan dan penentuan metode penelitian yang tepat untuk mencapai tujuan penelitian. Rancangan metode 
penelitian ini menggunakan metode kuantitatif karena untuk mengetahui pengaruh pendidikan dan pendapatan orang tua terhadap pendidikan anak nelayan. Dan metode pengumpulan data yang digunakan peneliti yaitu dengan menggunakan angket atau kuesioner, wawancara dan dokumentasi untuk menunjang hasil penelitian agar lebih akurat dan sesuai dengan yang diharapkan peneliti. Rancangan metode penelitian ini dengan bentuk gambar yaitu pengaruh pendidikan dan pendapatan orang tua terhadap tingkat pendidikan anak nelayan tradisional yang ditunjukkan pada skema di bawah ini :

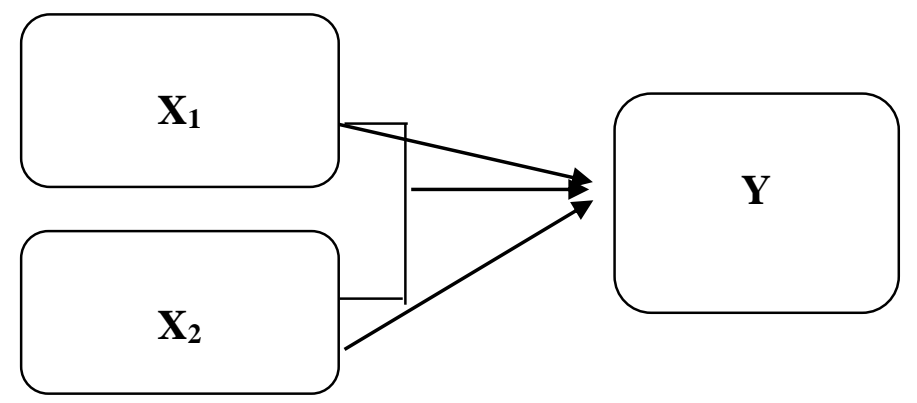

Variabel Bebas atau yang biasa disebut dengan $X$ pada penelitian ini adalah 1). Pendidikan orang tua yang dinyatakan dengan $X_{1}$ yaitu pendidikan formal. Pendidikan yang telah ditempuh oleh nelayan berupa pendidikan SD, SMP, SMA atau Perguruan Tinggi. Sedangkan variabel bebas

2) adalah pendapatan orang tua. Pada penelitian ini pendapatan orang tua dinyatakan dengan $X_{2}$.

3). Variabel terikat atau yang disebut dengan $Y$ pada penelitian ini adalah tingkat pendidikan anak nelayan tradisional Kecamatan Seruyan Hilir Kabupaten Seruyan.

Populasi dalam penelitian ini adalah seluruh Kepala Keluarga nelayan tradisional yang berada di Kecamatan Seruyan Hilir Kabupaten Seruyan yaitu yang berjumlah 583 nelayan.

Dengan menggunakan tabel Isaac dan Michael kesalahan 5\% dalam buku Sugiyono (2015), bila jumlah populasi 583 maka jumlah sampelnya 221. Karena populasi dalam penelitian ini heterogen atau berstrata maka sampel yang digunakan peneliti juga berstrata. Hasil Sampel diatas berdasarkan perhitungan:

$$
\begin{aligned}
& S M A=58 / 583 \times 221=21,98=22 \\
& S M P=175 / 583 \times 221=66,33=66 \\
& S D=350 / 583 \times 221=132,67=133
\end{aligned}
$$

Penentuan Sampel dilakukan secara acak atau random sampling dengan cara undian.

Ada beberapa asumsi yang menjadi pijakan pada penelitian ini adalah

1. Tingkat pendidikan orang tua menentukan bagaimana pendidikan anak, orang yang tingkat pendidikannya tinggi akan mempunyai wawasan yang jauh kedepan tentang pendidikan anaknya dibandingkan dengan yang berpendidikan rendah;

2. Besar kecilnya pendapatan dapat diartikan sebagai hasil yang diterima seseorang karena orang itu bekerja dan hasilnya bisa berupa uang atau barang. Semakin besar pendapatan maka kesejahteraan lebih terjamin dan semua kebutuhan terpenuhi dan jika pendapatan kecil maka tingkat kesejahteraan rendah dan tidak bisa memenuhi kebutuhan;

3. Tingkat pendidikan orang tua dan besar kecilnya pendapatan menentukan bagaimana pendidikan anak, orang yang tingkat pendidikannya tinggi akan mempunyai wawasan yang jauh kedepan tentang pendidikan anaknya dibandingkan dengan yang berpendidikan rendah; dan semakin besar pendapatan maka kesejahteraan lebih terjamin dan semua kebutuhan terpenuhi dan jika pendapatan kecil maka tingkat kesejahteraan rendah dan tidak bisa memenuhi kebutuhan. 
Adapun jenis instrumen yang digunakan dalam penelitian ini adalah : Kuisioner. Kuisioner digunakan untuk mengumpulkan data yang diperlukan peneliti yang berkaitan dengan Pendidikan, pendapatan orang tua dan tingkat pendidikan anak nelayan tradisional di Seruyan Hilir Kabupaten Seruyan tahun 2016. Dalam pembuatan instrument ini peneliti menggunakan kisi-kisi sebagai berikut

Tabel 1. Kisi-kisi Pembuatan Instrumen

\begin{tabular}{|c|l|c|c|}
\hline No & Variabel & Indikator & Item \\
\hline 1 & Pendidikan orang tua & $\begin{array}{c}\text { Tingkat SD } \\
\text { Tingkat SMP } \\
\text { Tingkat SMA } \\
\text { Perguruan Tinggi }\end{array}$ & 2 \\
\hline 2 & Pendapatan & Jumlah pendapatan & 5 \\
\hline 3 & $\begin{array}{l}\text { Tingkat Pendidikan } \\
\text { anak }\end{array}$ & $\begin{array}{c}\text { Tingkat SD } \\
\text { Tingkat SMP } \\
\text { Tingkat SMA } \\
\text { Perguruan Tinggi }\end{array}$ & 2 \\
\hline
\end{tabular}

Dalam penelitian ini, selain menggunakan metode pokok, yaitu metode angket penelitian, juga menggunakan metode bantu, adapun alat pengumpul data yang digunakan adalah

a. Kuisioner

b. Wawancara

c. Dokumentasi

Teknik Analisis data di gunakan setelah data terkumpul, maka data tersebut perlu dianalisis dalam rangka menguji kebenaran hipotesis dan juga memperoleh kesimpulan. Sesuai data yang dikumpulkan, yaitu data kuantitatif, maka dalam penelitian ini digunakan analisis statistik, analisis deskriptif dan regresi berganda.

\section{HASIL DAN PEMBAHASAN}

Penelitian dilakukan di Kecamatan Seruyan Hilir Kabupaten Seruyan. Waktu penelitian dilakukan selama 3 bulan di 8 desa yang berada di Kecamatan Seruyan Hilir Kabupaten Seruyan Kalimantan Tengah.

Analisis deskriptif dilakukan untuk menganalisis data yang terkumpul dan dipergunakan untuk mengindentifikasi variabel dalam penelitian. Pada jenjang SD berjumlah 133 dari 221 nelayan atau lebih dari separuh dari jumlah yang ada. Pada jenjang SMP berjumlah 66 nelayan atau tidak sampai sepertiga dari 221 jumlah nelayan yang ada. Sedangkan pada jenjang pendidikan SMA hanya sekitar 22 nelayan yang mengenyam pendidikan tersebut. Atau hanya berjumlah sepersepuluh dari jumlah 221 nelayan. 


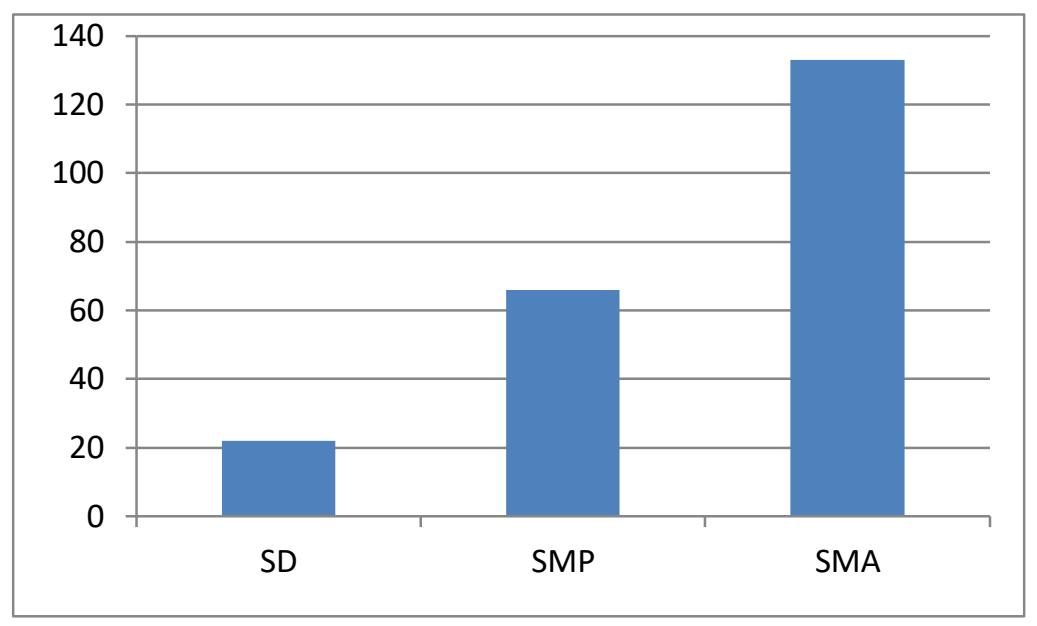

Gambar 1. Grafik Pendidikan Orang tua

Sedangkan pada tingkat pendapatan nelayan Kecamatan Seruyan Hilir pada rentang 30263591 sebanyak 60 frekuensi sekitar seperempat dari jumlah keseluruhan. Hal ini menunjukan bahwa hampir lebih dari separuh masyarakat nelayan Kecamatan seruyan Hilir sudah memiliki pendapatan sesuai dengan UMK Kabupaten Seruyan sebesar Rp. 2.310.998. Sesuai dengan Peraturan Gubernur Kalimantan Tengah, Nomor 50 Tahun 2015 tanggal 2 Nopember 2015, mengenai Upah Minimal Kabupaten (UMK) dan Upah minimum Sektoral Kabupaten (UMSK) yang berlaku mulai 1 Januari 2016.

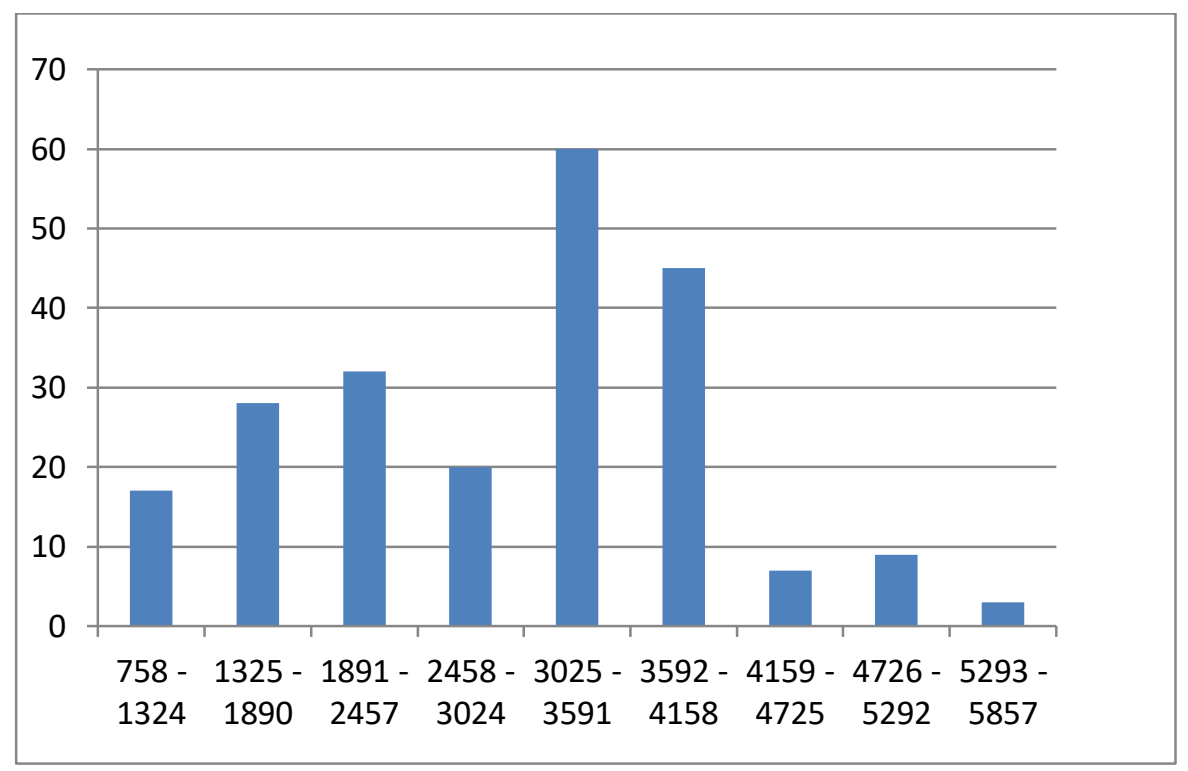

Gambar 2. GrafikPendapatan Orang tua

Pada Tingkat pendidikan anak nelayan tradisional di ambil dari anak nelayan yang tertinggi tingkat pendidikannya, karena tingginya tingkat pendidikan anak yang di capai merupakan keberhasilan orang tua atau nelayan dalam mendidik anak-anaknya. Pada anak nelayan yang berpendidikan SD sebanyak 69 anak dari jumlah anak nelayan yang ada menunjukan bahwa sekitar sepertiga anak nelayan yang berpendidikan SD hal ini menunjukan bahwa pendidikan SD sudah 
mengalami penurunan di bandingkan dengan jumlah pendidikan nelayan, sedangkan sebanyak 81 anak atau sekitar lebih dari seperti persen anak nelayan yang berpendidikan SMP hal ini menunjukan bahwa pendidikan anak nelayan pada tingkat SMP lebih banyak dari pada nelayan yang hanya mencapai tidak sampai sepertiga dari jumlah sampel yang ada, dan pada tingkat pendidikan SMA sebanyak 53 anak dari 221 anak nelayan, hal ini menunjukan hampir seperempat persen anak nelayan memiliki pendidikan tingkat SMA. Sedangkan tingkat pendidikan perguruan tinggi sebanyak 18 anak dari jumlah anak nelayan yang ada atau sekitar seperdelapan persen. Dengan seperdelapan persen anak yang memiliki tingkat pendidikan perguruan tinggi hal ini menunjukan bahwa anak nelayan tingkat pendidikannya tidak serendah pendidikan nelayan atau orang tua mereka.

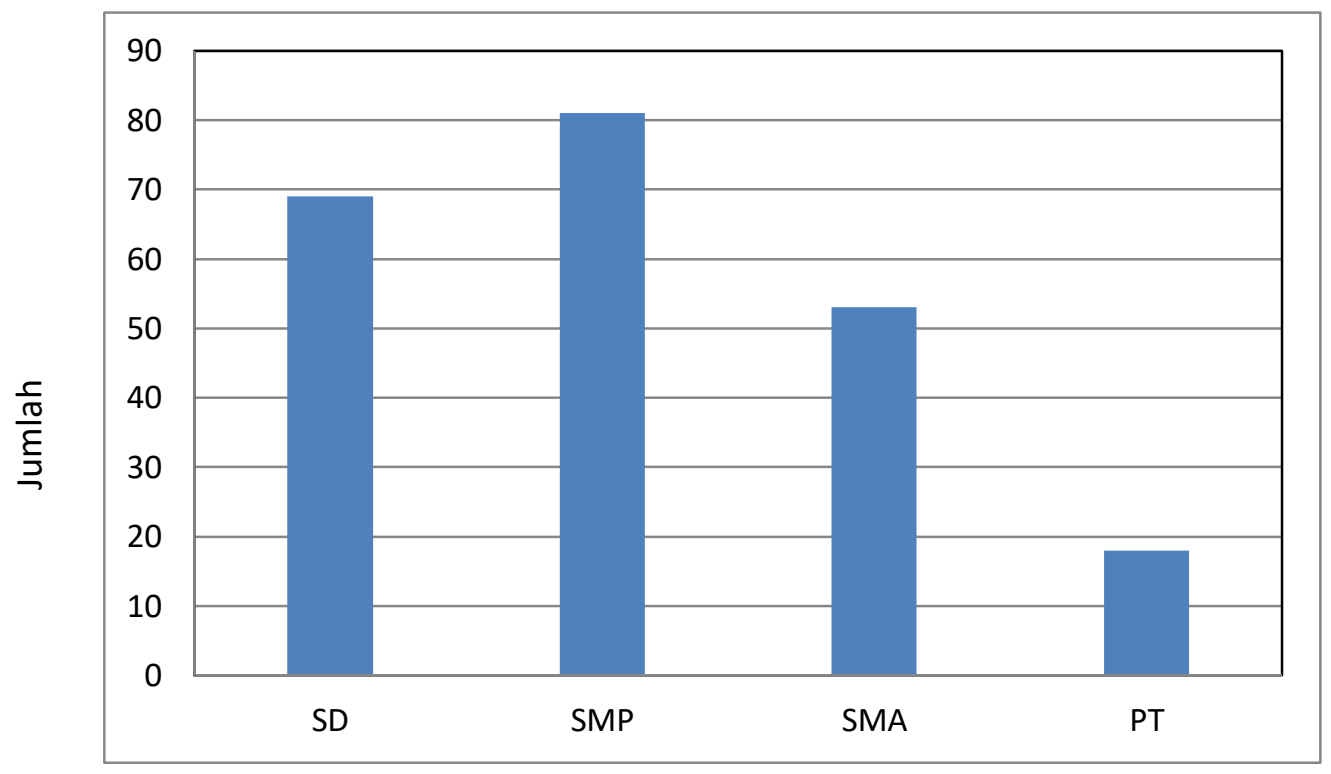

Pendidikan Anak Nelayan Tradisional

Gambar 3. GrafikPendidikan Anak Nelayan Kabupaten Seruyan

Peningkatan pada tingkat pendidikan anak bisa di karenakan beberapa faktor yang mempengaruhi. Dalam hal ini karena faktor pedidikan orang tua mereka lebih tinggi dari pendidikan orang tua-orang tua sebelumnya, dan juga di pengaruhi karena pendapatan nelayan atau orang tua mereka yang sudah cukup memadai.

Berdasarkan hasil perhitungan ternyata nilai Signifikansi pada t yaitu $0,00<0,05$, maka dengan demikian secara nyata variabel $\mathrm{X}_{1}$ berpengaruh terhadap $Y$.maka $\mathrm{H}_{0}$ ditolak atau $\mathrm{H}_{1}$ di terima, artinya ada pengaruh secara signifikan antara pendidikan nelayan terhadap pendidikan anak nelayan. Pada penelitian ini dapat disimpulkan bahwa pendidikan nelayan berpengaruh terhadap pendidikan anak nelayan. Perbedaan tingkat pendidikan orang tua menentukan bagaimana mereka dalam memberikan pandangan masa depan kepada anak-anaknya. Semakin tinggi pendidikan orang tua akan mempengaruhi pola pikir dalam mendidik anak, pendidikan orang tua yang tinggi memberi dampak positif kepada anak, karena setiap orang tua pasti berusaha untuk menjadikan anaknya lebih baik dari mereka dalam berbagai segi yang positif terutama dalam pendidikan. Gunarsah (2001) bahwa "orang tua mempunyai fungsi tidak hanya terbatas selaku penerus keturunan saja, tetapi dalam bidang pendidikan, orang tua merupakan sumber pendidikan utama, karena segala pengetahuan dan kecerdasan intelektual anak diperoleh pertama-tama dari orang tua sendiri". Menurut Ahmadi (12006:289) "orang tua yang berpendidikan akan memberikan perhatian yang lebih pada anak terutama dalam bidang pendidikan dengan harapan di masa mendatang kualitas kehidupannya lebih baik dari sebelumnya". Jadi orang tua yang berpendidikan tinggi akan mendidik anaknya minimal sama dengan pendidikan orang tua saat itu, bahkan kalau bisa melebihi pendidikan 
orang tua.

Berdasarkan perhitungan SPSS 16.0 maka didapatkan tingkat signifikansi menggunakan $\alpha=$ 5\% ( signifikansi 5\% atau 0.05 adalah ukuran standar yang sering digunakan dalam penelitian). Untuk menentukan tingkat signifikansi pengaruh $\mathrm{X}_{2}$ terhadap $\mathrm{Y}$ dilakukan dengan cara membandingkan nilai signifikansi hasil hitungan yaitu 0,00 dengan 0,05 terima Ho bilamana signifikansi $>0,05$., artinya menolak $\mathrm{Ha}$. Sebaliknya tolak Ho bilamana signifikansi $<0,05$, artinya menerima $\mathrm{Ha}$. Berdasarkan hasil perhitungan ternyata nilai Signifikansi yaitu $0,00<0,05$, maka dengan demikian secara nyata variabel $\mathrm{X}_{2}$ berpengaruh terhadap $\mathrm{Y}$. Dan karena Niai $\mathrm{P}$ value $<0.05$ $(0.00<0.05)$ maka $\mathrm{H}_{0}$ ditolak dan $\mathrm{H}_{1}$ diterima, artinya ada pengaruh secara signifikansi pendapatan nelayan terhadap tingkat pendidikan anak nelayan tradisional. Jadi dari penelitian ini dapat disimpulkan bahwa pendapatan nelayan berpengaruh terhadap pendidikan anak keluarga nelayan tradisional. Perbedaan tingkat pendidikan orang tua menentukan bagaimana mereka dalam memberikan pandangan masa depan kepada anak-anaknya. Dengan hasil penelitian bahwa ada pengaruh yang signifikan antara Pendidikan dan pendapatan orang tua terhadap pendidikan anak. Pendidikan dan pendapatan orang tua berpengaruh terhadap tingkat pendidikan anak nelayan menunjukan bahwa keluarga adalah kunci bagaimana tingkat pendidikan anak tersebut dapat di capai. Orang tua yang memiliki pola pikir yang luas di dukung dengan pendapatan yang besar memberikan kemudahan bagi anak nelayan untuk memperoleh fasilitas dalam menunjang pendidikan. Karena semakin tinggi tingkat pendidikan yang di capai anak maka tidak sedikit biaya yang harus di keluarkan orang tua. Dengan dukungan orang tua dan biaya sekolah yang tercukupi maka anak tidak terbebani dengan biaya yang ada. Mereka lebih bisa berekspresi dalam menyalurkan bakat dalam dunia pendidikan mereka. Hasil penelitian ini menunjukkan bahwa tingkat pendidikan dan tingkat pandapatan orang tua berpengaruh terhadap pendidikan anak nelayan secara simultan, artinya ada pengaruh secara signifikan antara pendidikan nelayan dan pendapatan nelayan secara bersama-sama terhadap pendidikan anak nelayan. Jadi dari kasus ini dapat disimpulkan bahwa pendidikan nelayan dan pendapatan nelayan secara bersama-sama berpengaruh terhadap pendidikan anak nelayan.

\section{Kesimpulan}

Penelitian ini bertujuan untuk mengetahui pengaruh pendidikan dan pendapatan orang tua terhadap pendidikan anak nelayan di Kecamatan seruyan Hilir Kabupaten Seruyan. Berdasarkan hasil penelitian dan pembahasan dapat diambil kesimpulan sebagai berikut:

1. Terdapat pengaruh pendidikan orang tua terhadap tingkat pendidikan anak nelayan tradisional di Kecamatan Seruyan Hilir Kabupaten Seruyan.

2. Terdapat pengaruh pendapatan orang tua terhadap tingkat pendidikan anak nelayan tradisional di Kecamatan Seruyan Hilir Kabupaten Seruyan.

3. Terdapat pengaruh pendidikan dan pendapatan orang tua terhadap tingkat pendidikan anak nelayan tradisional di Kecamatan Seruyan Hilir Kabupaten Seruyan.

\section{DAFTAR PUSTAKA}

Arif Rahman. 2009. Tesis. "Kelanjutan Pendidikan Dikalangan Anak Nelayan (Kasus, Desa Ujung Labuang, Kecamatan Suppa, Kabupaten Pinrang)"

Asri. 2000. Tesis. Analisis Faktor-Faktor yang Mempengaruhi Produktivitas Perikanan Laut: Studi Kasus Kapal Motor di Kota Padang, Tesis Universitas Andalas, Padang.

Depdikbud. 2003. Undang-Undang RI No. 20 Tahun 2003 Tentang Sistem Pendidikan Nasional. Semarang: Aneka Ilmu.

Depdikbud. Undang-Undang Republik Indonesia No. 4 Tahun 1979 tentang Kesejahteraan Anak,Semarang: Aneka Ilmu.

Depdikbud. Undang-Undang Republik Indonesia No. 23 Tahun 2002 tentang Perlindungan Anak, Semarang: Aneka Ilmu. 
Fauzi. A. 2005. Kebijakan Perikanan dan Kelautan (Isu, Sintesis, dan Gagasan), Gramedia Pustaka Utama, Jakarta.

Huraerah, Abu. 2006. Kekerasan terhadap Anak. Bandung: Penerbit Nuansa

Ismail, Z. 2004. Faktor-faktor yang mempengaruhi Penghasilan dan Pola Konsumsi Nelayan, Dampak Kerusakan Lingkungan Pesisir terhadap Kondisi Anonimous. Sosial Ekonomi Nelayan, Jakarta.

Imron. 2003. Nelayan Pustaka Intan Madani.

Kementerian Kelautan dan Perikanan Menteri Kelautan dan Perikanan Nomor 18/Men/2002. Tentang Rencana Strategis Pembangunan Kelautan Perikanan Tahun 2002-2004, Jakarta. Halaman 18

Kusnadi. 2007. Jaminan Sosial Nelayan, Pelangi Aksara, Yogjakarta

Maftukhah. 2007. Dengan Judul Pengaruh Kondisi Sosial Ekonomi Orang Tua Terhadap Prestasi Belajar Geografi Siswa Kelas VIII SMPN 1 Randudongkal Kabupaten Pemalang tahun 2007/2008

Monintja. 2009. Masyarakat Nelayan Indonesia.Yogyakarta PustakaIntan Madani.

Rahmad Maulidin. 2011. Tesis. "Pengaruh Pendapatan Petani Terhadap Pendidikan Anak Di Desa Tatebal Kec. Lenangguar Kab. Sumbawa".

Reddy Zaki Oktama. 2013. "Pengaruh Kondisi Sosial Ekonomi Terhadap Tingkat Pendidikan Anak Keluarga Nelayan Di Kelurahan Sugih waras Kecamatan Pemalang Kabupaten Pemalang Tahun 2013.

Rully Indrawan, R Poppy Yaniawati. 2014. Metodologi Penelitian. PT refika Aditama.

Sastrawidjaya. 2002. Masyarakat Pesisir, PT.Bandung

Sawitdan Sumiono dalam Rachmad Safa'at. 1998. "Perlindungan Hukum Hak Adat Kelautan dalam Pengelolaan Sumber daya Perikanan: Studi Kasus Nelayan Masangan di Kedung Cowek Surabaya," Tesis Magister Program Studi Ilmu Lingkungan, Pascasarjana Universitas Indonesia, Depok

Soerjono Soekanto. 2002. SosiologiSuatuPengantar. Jakarta:Rajawali Press

Soekartawi (1996) dalam Yustiarani (2008) Pendapatan Masyarakat Nelayan Pustaka Intan Madani. Sudjarwo, S. 2004. Buku Pintar Kependudukan. Jakarta: PT GramediaWidiasarana Indonesia.

Sugiyono. 2015. Statistik untuk Penelitian. Bandung: CV Alfabeta

Suharsimi Arikunto. 2006. ProsedurPenelitian. Jakarta: PT Rineka Cipta.

Sunardi dan Evers. 2002. Pendapatan. Jakarta Rajawali Press.

Sinta Dyana Santi. 2009. Pengaruh Kondisi Sosial Ekonomi Orang Tua Terhadap Prestasi Belajar Sosiologi Siswa Kelas XII IPS SMA N 1 Karang Tengah 